\title{
A simple expression to estimate the fatigue endurance of welded joints
}

\author{
Mirco Daniel Chapetti ${ }^{*}$ and Ceferino Steimbreger \\ Laboratory of Experimental Mechanics (LABMEX), INTEMA (Research Institute for Material Science and Technology), \\ CONICET - National University of Mar del Plata, J.B. Justo 4302, (B7608FDQ), Mar del Plata, Argentina.
}

\begin{abstract}
A simple expression is proposed to estimate the fatigue endurance of welded joints that can be used to understand and analyze in a simple way the influence of the main geometrical, mechanical and material effects (weld geometry, local geometry, material properties, residual stresses and size of defects). The proposed expression was derived from the results of the analysis of the fatigue strength of welds studied by means of a fracture mechanics approach that takes into account the fatigue behavior of short cracks by using the resistance curve method. For that purpose numerical simulation of transversely stressed butt, $\mathrm{T}$ and cruciform joints were performed.
\end{abstract}

\section{Introduction}

There exist several calculation methods for fatigue life analysis of welded joints, including the nominal stress method, hot spot method, notch stress method, local strain method, and fracture mechanics methods. Most of these methods are currently already either officially standardized $[1,2]$ or at least in internationally accepted recommendations [3]. However, there still exists a dominance of the traditional nominal stress method, which has been prevailing for over 45 years in the fatigue design of welded structures. To ensure that the full effect of the three key features dominating the fatigue life of welded joints (geometric stress concentrations, welding flaws, and residual stresses) are allowed for in design, most fatigue design rules consist of series of $\Delta \sigma-\mathrm{N}$ curves based on data obtained from constant amplitude fatigue tests on actual weldments [35], and employ classification methods of specifying design curves in terms of the fatigue strength at a given number of cycles (e.g. $2 \times 10^{6}$ or $10^{7}$ ). Since the stress concentration effect of the welded joint geometry is included, $\Delta \sigma$ refers to the nominal stress adjacent to the weld. Furthermore, to allow for the influence of residual stresses, the full stress range is used.

An important consequence of the geometric stress concentrations associated with most welded joints, the severity of which is usually compounded by the presence of welding flaws, is that fatigue cracks readily initiate and the life is dominated by fatigue crack growth [3-4]. This accounts for the drastic reduction in fatigue life resulting from the presence of a weld. It also explains why fracture mechanics is so relevant to the fatigue assessment of weldments. However, a simple form of the Paris-Erdogan power law is usually applied, given linear $\Delta \sigma-\mathrm{N}$ curves on a $\log -\log$ basis with a slope $m$ equal to that of the Paris law, compatible with the fatigue crack low for the material. Since $m$ is approximately 3 for most steels, $\Delta \sigma-N$ curves with slope 3 are widely adopted $[1-3,6]$. However, this procedure does not allow analyzing the influence of the different parameters defining the fatigue behavior.

To avoid some limitations on the analysis, a fracture mechanics methodology based on the resistance curve concept was proposed by Chapetti et al to analyze welded joint, accounting for the fatigue behavior of short cracks and considering the fatigue crack propagation threshold as a function of crack length $[7,8]$. Details of the method and some applications can be found on reference [7,8], [9] and [10]. In this work a simple expression to estimate the fatigue endurance of welded joints is proposed on the bases of the results of previous analysis and results [7-10].

\section{The fracture mechanics approach}

The method estimates the threshold for fatigue crack propagation as a function of crack length, $\Delta \mathrm{K}_{\mathrm{th}}$, and the fatigue crack propagation rate as a function of the difference between the applied driving force $\Delta \mathrm{K}$ and $\Delta \mathrm{K}_{\mathrm{th}}$, as follows [11]:

$$
\frac{d a}{d N}=C\left(\Delta K-\Delta K_{t h}\right)^{m}
$$

The threshold for fatigue crack propagation as a function of crack length $a$ is estimated by using the model proposed by Chapetti [12], as follows:

$\Delta K_{t h}=\Delta K_{d R}+\left(\Delta K_{t h R}-\Delta K_{d R}\right)\left[1-e^{-k(a-d)}\right] \quad a \geq d$

where $d$ is the average microstructural dimension (e.g. grain size, lath size, etc) and $\Delta K_{d R}$ and $k$ are given by [12]: 


$$
\begin{gathered}
\Delta K_{d R}=Y \Delta \sigma_{e R} \sqrt{\pi d} \\
k=\frac{1}{4 d}\left(\frac{\Delta K_{d R}}{\Delta K_{t h R}-\Delta K_{d R}}\right)
\end{gathered}
$$

where $\Delta \sigma_{e R}$ is the plain fatigue limit of the material. Figure 1 shows schematically the threshold curve given by equation (2) as a function of the square root of the crack length $a$.

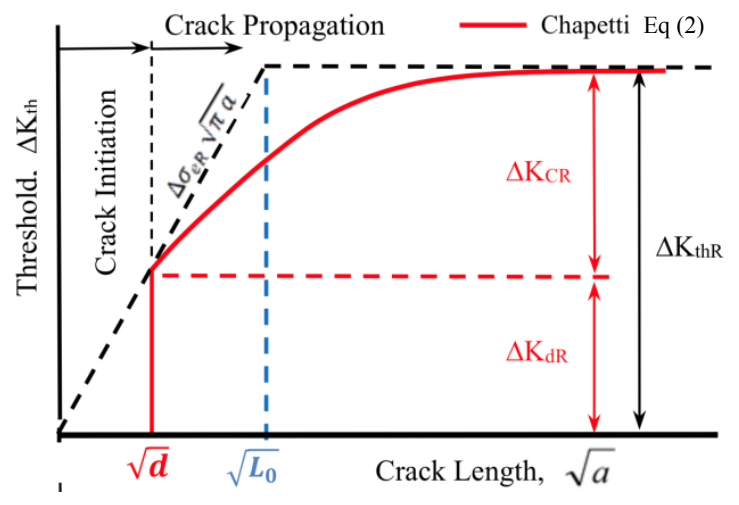

Fig. 1. $\Delta \mathrm{K}_{\mathrm{th}}$ as a function of the square root of $a$.

\section{Previous analysis and results}

Previous works have been done by using the proposed method in order to analyze the influence of different weld geometry parameters on the fatigue resistance of welded joints, like plate thickness, reinforcement angle, weld toe geometry, defect sizes and undercuts [7-10]. Results showed that the method allows understanding the influence of the different mechanical, geometrical and microstructural parameters on the definition of the fatigue resistance of the joint. In this way, it is possible to define which the main parameters for a given configuration are and to found the worst cases or limit values for them, according to the welding procedures and qualities. For instance, in a recent publication [10] we have shown that depth is the principal variable affecting fatigue behavior of butt-welded components with undercuts. Even though analysis based on continuum mechanics generally consider stress concentration factor as the controlling parameter, they fail to explain the importance of undercut depth in current regulations. In contrast, tolerable values of the undercut depth $D$ can be obtained with the method proposed for a given desired fatigue strength (endurance limit) of the welded joint. This is done by considering the tendency in Frost diagram for sharp notches, as can be observed in Fig 2 that shows the fatigue limit prediction as a function of the stress intensity factor $k_{\mathrm{t}}$ of the configuration for four different undercut depths $D$. Estimations were done considering the existence of defects of about $200 \mu \mathrm{m}$.

Curves plotted in Fig. 2 correspond to different undercut depths: $0.25,0.5,0.75$ and $1 \mathrm{~mm}$. For each depth, by varying notch radius the stress concentration factor $k_{\mathrm{t}}$ is modified. Likewise, different undercut geometry affect the shape of the applied driving force
$\Delta \mathrm{K}$ and a new value of the fatigue limit corresponds. It is easy to understand that the higher is the stress concentration factor the lower is the fatigue limit. However, it can be seen in Fig. 2 that the fatigue limit tends asymptotically to a minimum value for each undercut depth, being lower for deeper undercuts (size effect). If the notch radius is supposed to tend to zero, the undercut can be considered a crack of length equal to the undercut depth. Therefore, it can be thought that the minimum value is related to the fatigue limit of the welded joint without undercut, with an initial crack of length $a_{\mathrm{i}}=D$. A deeper analysis must consider the size of the non-propagating crack associated to the configuration $\Delta \mathrm{K}-\Delta \mathrm{K}_{\mathrm{th}}$ at the fatigue limit, which can be as long as $200-300 \mu \mathrm{m}$.

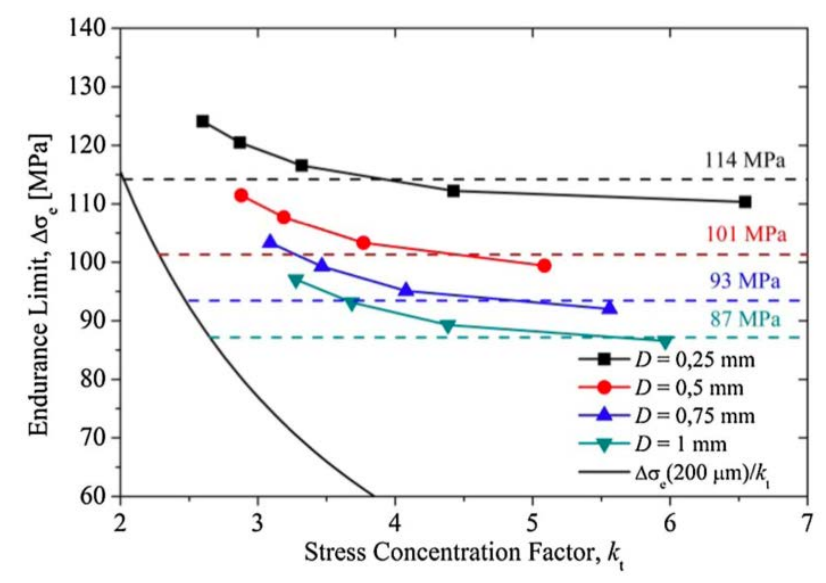

Fig. 2. Estimated fatigue limit or endurance $\left(\Delta \sigma_{\mathrm{e}}\right)$ of the joint as a function of $k_{\mathrm{t}}$ for butt welds with undercuts.

It is necessary to emphasize that predictions for high $k_{\mathrm{t}}$ (asymptotic trend in Fig 2) correspond to the worst scenario for a given undercut depth. Very high $k_{\mathrm{t}}$ values are seldom found in real undercuts but they allow to safely predicting tolerances.

Results exposed in reference [10] highlight the importance of not only undercut depth, but also threshold for fatigue crack propagation and nonpropagating crack length, when designing against fatigue damage. In search of a conservative simplification for the estimation of the lowest fatigue limit of butt-welds with undercuts, a simple relation was then established between fatigue limit, crack propagation threshold, notch depth and maximum non-propagating crack length [10]:

$$
\Delta \sigma_{e}=\frac{\Delta K_{t h}}{F\left[\pi\left(D+a_{n p-\max }\right)\right]^{f}}
$$

where $a_{\text {np-max }}$ is the maximum non-propagating crack length for a given notch depth, as indicated before, and $\Delta \mathrm{K}_{\text {th }}$ is the threshold value when $a=D+a_{\text {np-max }} . F$ and $f$ are constants that depend on the weld detail without undercut, i.e. reinforcement angle and thickness. Note that if reinforcement is ground $\left(180^{\circ}\right)$, then $F=1.12$ and $f=0.5$, as in a "through-thickness" crack. It is also important to note that in the analysis $\Delta \mathrm{K}_{\mathrm{th}}$ was roughly constant for $a>0.5 \mathrm{~mm}$ and equalize the fatigue threshold for long cracks ( $\left.\Delta \mathrm{K}_{\mathrm{thR}}\right)$. 
Finally, it is important to say that although fixed global geometry and loading condition were used in the analysis of the influence of undercuts, the proposed method can scientifically explain the effect and relevance of most of the mechanical and geometrical parameters, as was shown in references [7], [8], [9] and [10].

\section{The simplifying hypotheses}

The analysis carried out in references [7-10] includes all details related with the configuration and use only a few hypotheses related with the applied models. In the present work the idea is to use the different results obtained in previous analysis and look for a simplification to be use in standards in a simple way. The detailed analysis should help us to further improve these simplifications for future applications. The following hypotheses are applied to develop the simplification:

- The existence of crack-like defects in welded joints can be normally assumed, which eliminate the crack initiation stage of fatigue life. A review by Grover [13] suggested that even high-quality welds contain flaws up to a depth of about $100 \mu \mathrm{m}$. Other works observed initial crack-like defect depths of about 10-120 $\mu \mathrm{m}$ [14], 20$150 \mu \mathrm{m}$ [15] or $10-400 \mu \mathrm{m}$ [16], according to the welding conditions. In IIW guidelines [17] initial crack length of $50-150 \mathrm{~mm}$ is recommended for fracture mechanics applications. Radaj and Sonsino [18] have recommended an initial crack size $a_{\mathrm{i}}=100-250 \mu \mathrm{m}$ for life prediction in welded structures. Such defect depths clearly fall within the short crack regime. In this work, initial crack length $a_{\mathrm{i}}=200 \mu \mathrm{m}$ is considered for the analysis, but other values can be assumed.

- The weld toe is considered as a sharp corner. In this case the theoretical elastic stresses near to the surface would tend to infinity (singularity), but that is acceptable as crack-like initial defects exist and therefore the stresses at the surface are not required. This hypotheses was confirmed in references $[7,8]$, that showed that the stress concentration at a given depth $x\left(k_{\mathrm{tx}}\right)$ does not depend on the notch root radius $(\rho)$ when $x>0.2 \rho$. For instance, if the initial crack length is $100 \mathrm{~mm}$ the influence of notch root radius seems to have no important effect on the applied stress distribution for notch root radii less than $0.5 \mathrm{~mm}$. A greater toe radius would give lower stress concentrations, so that in such cases the assumption would be conservative.

- Through thickness cracks are conservatively considered. The cracks, initiated at weld toes and guided by them along the surface, quickly develop a small aspect ratio, so that it is possible to conservatively consider the geometric factor $Y$ equal to 1.12 .

- In order to estimate fatigue limit (or endurance for high cycle fatigue), the threshold for fatigue crack propagation as a function of crack length should be necessary considered. The threshold should include the short crack regime, where it depends on the crack length. This threshold curve depends mainly on the threshold for long crack and the minimum microstructural threshold associated to the fatigue limit of the material where the crack nucleates. This curve can be simplified according to the configuration associated with the fatigue limit, which sometimes includes non-propagating cracks. This should be considered in the analysis in order to look for further simplifications.

\section{The analysis}

Numerical simulations of transversely stressed butt, $\mathrm{T}$ and cruciform joints were carried out for the analysis. Tensile and bending loading were considered for all three joints, getting six different configurations for the analysis. The fracture mechanics approach introduced in section 2 and detailed in references [7-10] was applied. A $19 \mathrm{~mm}$ thick plate was considered in the analysis for all cases. Reinforcement angle was $33^{\circ}$ for the buttwelded joint and $45^{\circ}$ for the $\mathrm{T}$ and cruciform welds. Gusset in $\mathrm{T}$ and cruciform models was $50 \mathrm{~mm}$ long and $19 \mathrm{~mm}$ thick, whereas fillet leg was $10 \mathrm{~mm}$. A hole with a radius of $1 \mathrm{~mm}$ was adopted at the root. Simulation was purely geometric and residual stresses resulting from the welding process were not accounted for.

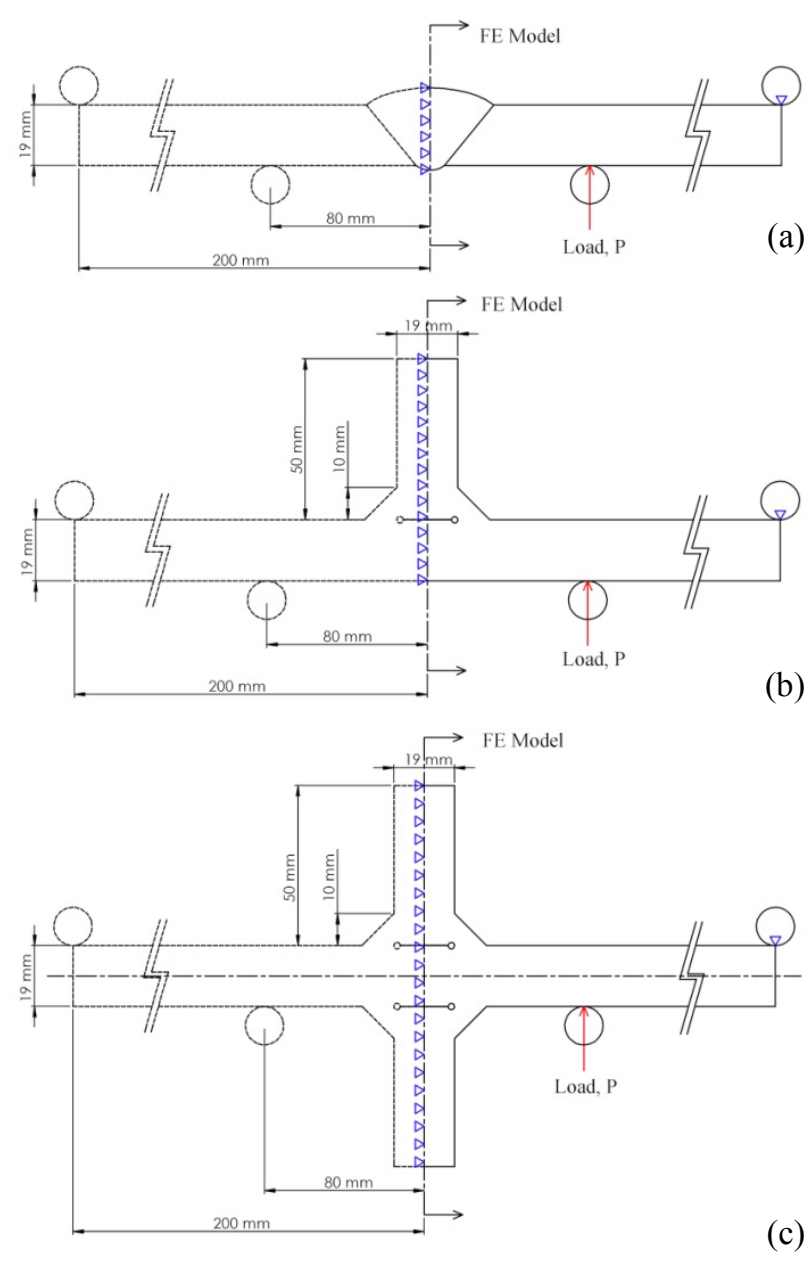

Fig. 3. FE model for (a) butt joint, (b) T-joint and (c) Cruciform joint. 
Fig. 3 illustrates symmetry and schematically displays load configurations, boundary conditions and overall geometry. Four point bending and pure traction were applied to the samples. Two dimensional linear elastic analyses were used and symmetry was assumed in all the models.

Stress intensity factor calculations were achieved following software procedure for fracture mechanic simulations [ABAQUS]. Then, cracks were introduced as "seam cracks" at the weld toe, where the crack is more likely to nucleate. Mesh consisted in 6-node quadratic plane strain triangles at the crack front, which use a modified second-order interpolation and 8-node biquadratic plane strain quadrilateral elements in the rest of the model. Since the model is linear elastic, it is recommended to include a square root singularity at the crack tip, which improves accuracy of the stress intensity factor calculation.

Table 1 indicates the six analyzed configurations. The parameter $M_{\mathrm{k}-200}$ represents the stress concentration generated by the configuration (geometry and loading) at a depth equal to $200 \mu \mathrm{m}$, which is taken as the initial crack length $a_{\mathrm{i}}$ in the present analysis. It means that a maximum crack-like defect of $200 \mu \mathrm{m}$ is considered.

Table 1. Analyzed configurations.

\begin{tabular}{|c|c|c|c|}
\hline Joint & Loading & Configuration & $\boldsymbol{M}_{\mathbf{k}-\mathbf{2 0 0}}$ \\
\hline \multirow{2}{*}{ Butt } & Tensile & B-T & 1,48 \\
\cline { 2 - 4 } & Bending & B-B & 1,51 \\
\hline \multirow{2}{*}{$\mathrm{T}$} & Tensile & T-T & 1,58 \\
\cline { 2 - 4 } & Bending & T-B & 1,73 \\
\hline $\begin{array}{c}\text { Cruciform } \\
\text { X }\end{array}$ & Tensile & X-T & 1.9 \\
\cline { 2 - 4 } & Bending & X-B & 1,52 \\
\hline
\end{tabular}

\section{Results and proposal}

Table 2 shows the main results we need for the proposal: the estimated fatigue limit (endurance) for each configuration $\left(\Delta \sigma_{\mathrm{e}}\right)$, the recommendation given by IIW for Butt, T and cruciform joints, and the parameter $M_{\mathrm{k} 200}$.

Table 2. Results.

\begin{tabular}{|c|c|c|c|c|}
\hline Joint & $\begin{array}{c}\Delta \mathbf{K}_{a \mathrm{i}=\mathbf{2 0 0}} \\
{\left[\mathrm{MPa} \mathrm{m}^{1 / 2}\right]}\end{array}$ & $\begin{array}{c}\Delta \boldsymbol{\sigma}_{\mathrm{e}} \\
{[\mathrm{MPa}]}\end{array}$ & $\begin{array}{c}\Delta \boldsymbol{\sigma}_{\mathrm{e}} \mathbf{I I W} \\
{[\mathrm{MPa}]}\end{array}$ & $\boldsymbol{M}_{\mathbf{k}-\mathbf{2 0 0}}$ \\
\hline B-T & Tensile & 95 & 90 & 1,48 \\
\hline B-B & Bending & 93 & & 1,51 \\
\hline T-T & Tensile & 89 & 85 & 1,58 \\
\hline T-B & Bending & 81 & & 1,73 \\
\hline X-T & Tensile & 92 & 71 & 1,52 \\
\hline X-B & Bending & 74 & & 1,9 \\
\hline
\end{tabular}

The analysis was carried out considering residual stresses and an effective load ratio $R$ equal to 0.5 , with a threshold for fatigue crack propagation for a crack length equal to $200 \mu \mathrm{m}$ of about $4 \mathrm{MPa} \mathrm{m}{ }^{1 / 2}$. Details of the numerical analysis and results will be published soon. The fatigue endurance is estimated by making the applied $\Delta \mathrm{K}$ equal to the threshold $\Delta \mathrm{K}_{\mathrm{th}}$ for the initial crack length $a_{\mathrm{i}}$, using the following expression:

$$
\Delta K=Y M_{k-a_{i}} \Delta \sigma_{e} \sqrt{\pi a_{i}}=\Delta K_{t h}
$$

From which we get the following general expression for fatigue endurance estimation for welded joints:

$$
\Delta \sigma_{e}=\frac{\Delta K_{t h}}{Y M_{k-a_{i}} \sqrt{\pi a_{i}}}
$$

With $a_{\mathrm{i}}=200 \mu \mathrm{m}$ and $Y=1,12$ (through thickness cracks) we get the following simplification:

$$
\Delta \sigma_{e}=\frac{35 \Delta K_{t h}}{M_{k-200}}
$$

Fig 4 shows the fatigue endurance proposed by the IIW document for the three different joints, together with the estimated ones for the six analyzed configurations given by expression (8) for $\Delta \mathrm{K}_{\mathrm{th}}=4 \mathrm{MPa} \mathrm{m}^{1 / 2}$, all as a function of the parameter $M_{\mathrm{k}-200}$.

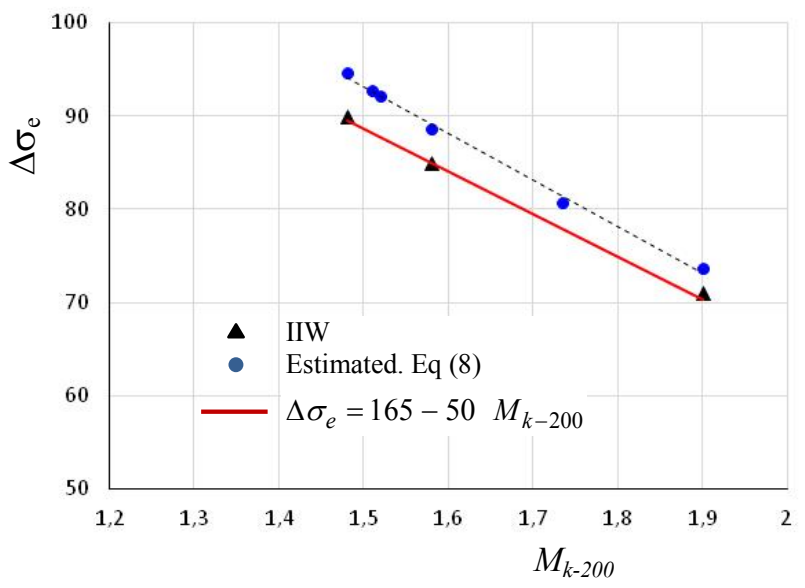

Fig. 4. Fatigue endurance as a function of the macroscopic stress concentration $M_{\mathrm{k}-200}$.

Fig 4 shows a clear linear relationship between the endurance limit and the parameter $M_{\mathrm{k}-200}$. For the fatigue endurances recommended by IIW the following simple expression can be proposed to explain the trend:

$$
\Delta \sigma_{e}=165-50 \quad M_{k-200}
$$

where the fatigue endurance $\Delta \sigma_{\mathrm{e}}$ is in $\mathrm{MPa}$.

\section{Concluding remarks}

After different studies and analysis done by using fracture mechanics methodologies to understand the influence of the different mechanical, geometrical and material parameters on the fatigue behavior of welded joints, important conclusions and hypotheses can be related in order to look for simple and useful expressions 
and procedures to estimate their fatigue endurances. Results show that the fatigue endurance of welded joints can be explain in the simple way by accounting for the stress concentration at a given depth from the fatigue crack initiation point, given by the macro-geometry of the joint $\left(M_{\mathrm{k}-a \mathrm{i}}\right)$. These results open an important door to look for new phenomenological and theoretical way to develop a simple procedure to estimate the fatigue endurance of welded joints for engineering applications. We think that much effort should be done in this way.

\section{References}

1. Fatigue design and assessment of steel structures code of practice, British Standard BS 7608 (1993).

2. Guide on methods for assessing the acceptability of flaws in metallic structures, British Standard BS 7910 (1999).

3. A. Hobbacher. IIW XIII-2151r1-07 XV-1254r1/07 (2007).

4. T. A. Gurney. Fatigue of welded structures, Cambridge University Press (1978).

5. AWS structural welding code, 9th edn, AWS, Miami, FL, USA (1985).

6. Guideline for fatigue design of steel constructions, JSSC, Gihodo Ltd, Tokyo, Japan, 1993.

7. M.D. Chapetti, J. Belmonte, T. Tagawa and T. Miyata. IIW X-1545-03 XIII-1971-03 (2003)

8. M.D. Chapetti, J. Belmonte, T. Tagawa and T. Miyata. J Sci Tech Weld J, 9, 430 (2004).

9. M.D. Chapetti and L. Jaureguizahar. Int J Fatigue 43, 43 (2012).

10. C. Steimbreger and M.D. Chapetti. Int. J. Fatigue 105, 296 (2017).

11. C. Molina and M.D. Chapetti. Int J Fatigue 108, 47 (2018).

12. M.D. Chapetti. Int J Fatigue 25, 1319 (2003).

13. J.L. Grover. Int Conference on Fatigue of Welded Construction, Brighton, 275 (1987).

14. I.F. Smith and R.A. Smith. Fatigue Fract Eng Mater Struct 5, 151 (1982).

15. E.G. Signes, R.G. Baker, H.D. Harrison and F.M. Burdekin. Weld J 14, 108 (1967).

16. F. Watkinson, P.H. Bodger and J.D. Harrison. Int Conference on Fatigue Welded Structures. The WI, 97 (1970).

17. B. Jonsson. IIW Guidelines on weld quality in relationship to fatigue strength (2016).

18. D. Radaj and M. Sonsino. Fatigue assessment of welded joints by local approaches. Abington Publishing (1998). 